Article

\title{
Application of Next Generation Semiconductor-Based Sequencing for the Identification of Apis mellifera Complementary Sex Determiner (csd) Alleles from Honey DNA
}

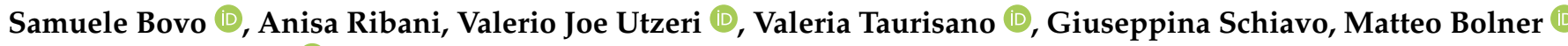 \\ and Luca Fontanesi * (D) \\ Department of Agricultural and Food Sciences, University of Bologna, Viale Giuseppe Fanin 46, \\ 40127 Bologna, Italy; samuele.bovo@unibo.it (S.B.); anisa.ribani2@unibo.it (A.R.); \\ valeriojoe.utzeri2@unibo.it (V.J.U.); valeria.taurisano2@unibo.it (V.T.); giuseppina.schiavo2@unibo.it (G.S.); \\ matteo.bolner2@unibo.it (M.B.) \\ * Correspondence: luca.fontanesi@unibo.it; Tel.: +39-051-2096535
}

check for updates

Citation: Bovo, S.; Ribani, A.; Utzeri, V.J.; Taurisano, V.; Schiavo, G.; Bolner, M.; Fontanesi, L. Application of Next Generation Semiconductor-Based Sequencing for the Identification of Apis mellifera Complementary Sex Determiner (csd) Alleles from Honey DNA. Insects 2021, 12, 868. https:// doi.org/10.3390/insects12100868

Academic Editor: Yehuda

Y. Ben-Shahar

Received: 19 August 2021

Accepted: 21 September 2021

Published: 24 September 2021

Publisher's Note: MDPI stays neutral with regard to jurisdictional claims in published maps and institutional affiliations.

Copyright: (c) 2021 by the authors. Licensee MDPI, Basel, Switzerland. This article is an open access article distributed under the terms and conditions of the Creative Commons Attribution (CC BY) license (https:// creativecommons.org/licenses/by/ $4.0 /)$.
Simple Summary: Honey contains traces of the DNA of the honey bees that produced it. This environmental DNA can therefore be used to investigate the genome of the honey bees. In this study, we used a next generation sequencing technology to analyze the variability of a key gene of Apis mellifera L., the complementary sex determiner ( $c s d)$ gene, using honey environmental DNA as a source of honey bee DNA. This gene determines the sex of the bees. Two different alleles at this locus are needed to produce females whereas males have only one copy of this gene as they are haploid. In case two identical alleles are present in a diploid individual, the larvae are not vital and are discarded by the workers. Therefore, there is an advantage in maintaining a large csd diversity in honey bee populations. In light of the recent decline in honey bee populations, it is important to monitor the allele variability at this gene. The applied methodology provided a new strategy to disclose the genetic diversity at the $\operatorname{csd}$ gene at the population-wide level and identify most, if not all, csd alleles present in the colonies in a single analysis.

Abstract: The complementary sex determiner (csd) gene plays an essential role in the sex determination of Apis mellifera L. Females develop only if fertilized eggs have functional heterozygous genotypes at this gene whereas males, being haploids, are hemizygous. Two identical csd alleles produce non vital males. In light of the recent decline in honey bee populations, it is therefore important to monitor the allele variability at this gene. In this study, we tested the application of next generation semiconductor-based sequencing technology (Ion Torrent) coupled with environmental honey DNA as a source of honey bee genome information to retrieve massive sequencing data for the analysis of variability at the hypervariable region (HVR) of the csd gene. DNA was extracted from 12 honey samples collected from honeycombs directly retrieved from 12 different colonies. A specifically designed bioinformatic pipeline, applied to analyze a total of about 1.5 million reads, identified a total of 160 different $c s d$ alleles, $55 \%$ of which were novel. The average number of alleles per sample was compatible with the number of expected patrilines per colony, according to the mating behavior of the queens. Allele diversity at the csd could also provide information useful to reconstruct the history of the honey.

Keywords: environmental DNA; genetic diversity; honey bee; inbreeding; polymorphism; population genomics; variability

\section{Introduction}

Honey bees (Apis mellifera L., 1758) are haplodiploid organisms like all species of the insect order Hymenoptera [1]. In these organisms, females develop from fertilized oocytes, which form diploid embryos, whereas males develop from unfertilized eggs, 
which produce haploid embryos [1,2]. This sex determination mechanism can work if females are heterozygous at a key genetic factor, the complementary sex determiner (csd) gene which, in this genotype condition, drives the sex determination cascade essential to produce female bees [3]. Drones, which are haploid, have only one copy of the csd gene and are defined as hemizygous. In diploid honey bees, if two functional identical csd alleles are present (i.e., homozygosity), the condition results in being similar to hemizygosity and the honey bees develop into sterile diploid male forms [3-5]. These diploid males are eliminated by the worker bees within three days of hatching as they would constitute a drain in colony resources and energy [6,7]. These eliminated larvae, however, cause decreased brood viability and, in turn, can affect colony growth and productivity due to the lack of worker bees [8-10].

The natural queen mating system, which involves polyandry and mating flight far from the original hives, decreases the risk of co-occurrence of identical csd alleles in fertilized eggs $[10,11]$. The frequency of identical csd alleles in diploid genomes could, however, increase with an increased level of inbreeding in honey bee populations, which can occur in close populations under selective breeding programs $[6,8,9,12-14]$. Therefore, the maintenance of a high allelic diversity at the csd gene is an important factor for the survival of honey bee populations, and several modeling systems have investigated the related genetic mechanism before and after this gene was recognized as the sex determination locus [15-22]. The number and distribution of csd alleles is particularly relevant in light of the problems that a reduction in the viability of the colonies could have in the context of honey bee population decline [23].

The csd gene is constituted by nine exons [3]. Exons 6, 7, and 8 encode the potential specifying domain that is under balancing selection $[20,22]$. Most of the allelic variation of the $c s d$ gene resides in the hypervariable region (HVR) encoded by exon $8[3,21,23-27]$. The HVR, flanked by conserved regions at both ends, consists of a variable number of A/T-rich nucleotide repeats, which mainly encode for a variable number of asparagine $(\mathrm{N})$ and tyrosine $(\mathrm{Y})$ residues. This repeat-rich region has a very high mutation rate, estimated to be higher than twice that of microsatellite regions, which can frequently result in the generation of new alleles [21].

The level of diversity of this highly repetitive gene region has been investigated in different honey bee populations by several studies that mostly used Sanger sequencing of the HVR amplified from drones [21,23-26,28,29]. These studies identified a high number of $c s d$ protein allele sequences that have been recently compiled in a scientific note [27].

Honey is a unique source of environmental DNA (eDNA) as it contains traces of all the organisms that directly or indirectly contributed to produce it or were part of the hive environment where it was produced [30-38]. Therefore, honey also contains the DNA of the honey bees that produced it [33]. We recently analyzed honey bee mitochondrial DNA (mtDNA) variability using honey as a source of DNA [33] and produced a distribution map of the main A. mellifera mtDNA lineages in Italy [34]. We also applied whole DNA shotgun sequencing approaches using next generation sequencing platforms for metagenomic analyses of honey DNA, and established a method to identify the $A$. mellifera subspecies using variants sequenced and retrieved from this matrix [31,32]. The method offers the possibility of analyzing more than one colony and many queen lineages at the same time, considering that honey (as it is usually prepared by the beekeepers) is derived from several families or even more than one apiary $[33,34,37,38]$. Therefore, honey can be used to obtain a quite extensive population-wide picture of the presence of honey bee genetic features including information on variability at the $c s d$ gene. Kolics et al. [29] already tested the possibility of obtaining sequence information of the $c s d$ HVR using amplicons produced from honey DNA and Illumina next generation sequencing.

Next generation semiconductor-based sequencing technology (i.e., the Ion Torrent platform) could provide a convenient high-throughput DNA sequencing system for routine applications due to the possibility of sequencing amplicons that are not obtained with specific adaptor primers, which could be relevant for target amplification from highly 
degraded DNA such as the DNA that can be extracted from the honey [36-38] or other processed food products including meat and dairy products $[39,40]$. On the other hand, sequencing data from this technology should be appropriately analyzed to overcome the problem derived by the homopolymeric regions, which increase the sequencing error rate $[39,40]$.

In this study, we tested the possibility to analyze the csd HVR from honey DNA by using a next generation semiconductor-based sequencing platform combined with a specifically designed bioinformatic pipeline that was able to retrieve highly reliable protein deduced csd alleles from this targeted region.

\section{Materials and Methods}

\subsection{Honey Samples and DNA Extraction}

We analyzed twelve polyfloral honey samples (hereafter referred to as H1-H12) produced by nine different beekeepers in 2020 from twelve different apiaries located in five different provinces of the Emilia-Romagna region, north of Italy (Table 1). Honey samples were collected directly from one honeycomb retrieved from 12 different colonies. Seven different samples/apiaries were linked to seven different beekeepers, three other different samples/apiaries were linked to another beekeeper, and the last two samples/apiaries were linked to another different beekeeper (Table 1).

Table 1. Honey samples and their geographic origin (province), number of sequenced reads, and csd alleles identified from the sequencing data.

\begin{tabular}{|c|c|c|c|c|c|c|}
\hline Sample ID ${ }^{1}$ & Province & No. of Reads & $\begin{array}{c}\text { No. of } \\
\text { Retained } \\
\text { Reads (\%) }{ }^{2}\end{array}$ & $\begin{array}{c}\text { No. of } c s d \\
\text { Protein Alleles }\end{array}$ & $\begin{array}{c}\text { No. of Private } \\
\text { csd Alleles (\%) }\end{array}$ & $\begin{array}{c}\text { No. of New csd } \\
\text { Alleles } \\
\text { (Private) }^{5}\end{array}$ \\
\hline H1 & Bologna & 173,064 & $149,678(86.4)$ & 17 & $8(47.1)$ & $9(7)$ \\
\hline $\mathrm{H} 2^{\circ}$ & Reggio Emilia & 75,454 & $72,027(95.4)$ & 13 & $4(30.8)$ & $5(3)$ \\
\hline H3 & Piacenza & 414,002 & $269,785(64.8)$ & 40 & $16(40.0)$ & $13(11)$ \\
\hline $\mathrm{H} 4^{\circ}$ & Reggio Emilia & 84,307 & 82,056 (97.3) & 14 & $2(14.3)$ & $5(0)$ \\
\hline $\mathrm{H} 5^{\circ}$ & Reggio Emilia & 397,333 & $296,982(74.7)$ & 20 & $7(35.0)$ & $5(3)$ \\
\hline H6 & Ferrara & 34,350 & $33,503(97.5)$ & 13 & $3(23.1)$ & $7(3)$ \\
\hline H7 & Piacenza & 99,979 & $48,369(48.3)$ & 23 & $11(47.8)$ & $12(11)$ \\
\hline $\mathrm{H} 8$ & Bologna & 41,741 & $37,431(89.7)$ & 17 & $4(23.5)$ & $3(1)$ \\
\hline $\mathrm{H} 9$ * & Piacenza & 97,735 & $73,994(75.7)$ & 33 & $13(39.4)$ & $16(11)$ \\
\hline H10 & Rimini & 70,307 & $53,728(75.1)$ & 61 & $41(67.2)$ & $40(37)$ \\
\hline H11* & Piacenza & 35,183 & $29,865(84.9)$ & 10 & $2(20.0)$ & $3(1)$ \\
\hline $\mathrm{H} 12$ & Piacenza & 1341 & $1220(91.0)$ & 10 & $3(30.0)$ & $0(0)$ \\
\hline
\end{tabular}

${ }^{1}$ Samples provided by the same beekeeper are marked with the same symbol $\left({ }^{*}\right.$ or $\left.{ }^{\circ}\right) .{ }^{2}$ Reads coding for valid alleles (see quality checks described in Section 2.4.2). Percentage is relative to the analyzed sample over the number of all reads obtained for that sample. ${ }^{3}$ Number of valid alleles determined after the application of the filtering criteria reported in Section 2.4.2. ${ }^{4}$ Number of csd protein alleles identified only in that sample. The percentage is over the total number of $c s d$ protein alleles obtained for that sample. ${ }^{5}$ Number of new csd protein alleles. The number of private alleles that were also new is reported within brackets.

These samples were used for DNA extraction, following the protocol previously described [30-33]. Briefly, honey samples were pre-treated by adding ultrapure water in $50 \mathrm{~g}$ of starting material divided into four aliquots of $12.5 \mathrm{~g}$. After vortexing and incubating at $40{ }^{\circ} \mathrm{C}$ for $1 \mathrm{~min}$, the tubes were centrifuged at $5000 \times \mathrm{g}$ at room temperature for $25 \mathrm{~min}$. The resulting supernatant was eliminated and $5 \mathrm{~mL}$ of ultrapure water was added in each tube and then the content of the four tubes was merged in a single $50 \mathrm{~mL}$ tube. A second centrifugation at $5000 \times g$ for $25 \mathrm{~min}$ at room temperature followed and the supernatant was discarded. The resulting pellet was resuspended in $0.5 \mathrm{~mL}$ of ultrapure water and transferred in a $1.5 \mathrm{~mL}$ tube containing about 12 glass beads $(500 \mu \mathrm{m})$ and vortexed for 
$3 \mathrm{~min}$. The sample was then transferred in a new $1.5 \mathrm{~mL}$ tube removing the beads and stored at $4{ }^{\circ} \mathrm{C}$. DNA extraction was performed using $1 \mathrm{~mL}$ of CTAB buffer [ $2 \%(w / v)$ cetyltrimethylammonium bromide; $1.4 \mathrm{M} \mathrm{NaCl} ; 100 \mathrm{mM}$ Tris-HCl; $20 \mathrm{mM}$ EDTA; $\mathrm{pH}$ 8.0], with the addition of $5 \mu \mathrm{L}$ of RNase A solution $(10 \mathrm{mg} / \mathrm{mL})$ and $30 \mu \mathrm{L}$ of proteinase $\mathrm{K}$ solution $(20 \mathrm{mg} / \mathrm{mL})$. Tubes were then incubated at $65^{\circ} \mathrm{C}$ for $90 \mathrm{~min}$ after gently mixing, and centrifuged for $10 \mathrm{~min}$ at $16,000 \times \mathrm{g}$. A total of $700 \mu \mathrm{L}$ of the obtained supernatant was transferred into a new tube containing $500 \mu \mathrm{L}$ of chloroform/isoamyl alcohol (24:1) solution, vortexed for $30 \mathrm{~s}$ and then centrifuged at $16,000 \times \mathrm{g}$ for $15 \mathrm{~min}$ at room temperature. The supernatant was transferred in a new $1.5 \mathrm{~mL}$ tube and the DNA was isolated and purified in two steps with isopropanol and then ethanol $70 \%$. DNA was finally resuspended with $30 \mu \mathrm{L}$ of sterile water and stored at $-20^{\circ} \mathrm{C}$.

Extracted DNA was quality checked in a TBE $1 \%$ agarose gel after staining with $1 \times$ GelRed Nucleic Acid Gel Stain (Biotium Inc., Hayward, CA, USA) and the concentration was measured using a Qubit 2.0 fluorimeter (Thermo Fisher Scientific, Waltham, MA, USA). This quality control analysis showed that the extracted DNA from all honey samples was degraded, as expected, confirming previous evaluations [33,36-38].

\subsection{PCR Amplification of the csd Region}

The csd HVR was amplified using a primer pair reported by Hyink et al. [28], also used by Zareba et al. [23]: forward: 5'-TATCGAGAAAsATCGAAAGAACGAT-3', reverse: 5'-ATTGAAATCCAAGGTCCCATTGGT-3'. Amplifications were performed on a 2700 Thermal Cycler (Life Technologies, Waltham, MA, USA). Reactions were run in a total volume of $20 \mu \mathrm{L}$ including KAPA HiFi HotStart Mastermix (Roche, Basel, Switzerland); 10 pmol of each primer; $40 \mathrm{ng}$ of template DNA. The PCR profile was the following: initial denaturation step at $95^{\circ} \mathrm{C}$ for $3 \mathrm{~min} ; 35$ cycles of alternate temperatures $\left(20 \mathrm{~s}\right.$ at $98{ }^{\circ} \mathrm{C}, 15 \mathrm{~s}$ at $51^{\circ} \mathrm{C}, 30 \mathrm{~s}$ at $72{ }^{\circ} \mathrm{C}$ ); and a final extension step at $72{ }^{\circ} \mathrm{C}$ for $1 \mathrm{~min}$. Obtained amplicons were electrophoresed on $2.5 \%$ agarose gels in TBE $1 \times$ buffer and then visualized with $1 \times$ GelRed Nucleic Acid Gel Stain (Biotium Inc., Hayward, CA, USA).

\subsection{Next Generation Sequencing}

Sequencing of the obtained amplicons was carried out following the protocol already described [41] with a few modifications. Briefly, PCR products obtained from each honey DNA sample using csd primers were purified with ExoSAP-IT ${ }^{\circledR}$ (USB Corporation, Cleveland, OH, USA) and then sequenced using an Ion S5-Ion Chef System (Thermo Fisher Scientific Inc., Waltham, MA, USA). A total of 12 libraries were produced by end-repair and ligation of the DNA fragments with a specific barcode using the Ion Xpress ${ }^{\mathrm{TM}}$ Plus Fragment Library and Ion Xpress ${ }^{\mathrm{TM}}$ Barcode Adapter 1-32 kits (Thermo Fisher Scientific Inc.). Each library was quantified with the Ion Library TaqMan Quantitation Kit (Thermo Fisher Scientific Inc.) by qPCR with the QuantStudio ${ }^{\text {TM }} 7$ Pro Real-Time PCR System (Thermo Fisher Scientific Inc.). Libraries were first clonally amplified by emulsion PCR and sequenced following the manufacturer's instructions using the Ion $510^{\mathrm{TM}}$ and Ion $520^{\mathrm{TM}}$ and Ion $530^{\mathrm{TM}}$ Kit-Chef after having pooled them for sequencing in one Ion 520 chip (Thermo Fisher Scientific Inc.).

\subsection{Bioinformatic and Data Analyses}

\subsubsection{Read Filtering and Identification of $c s d$ Sequences}

Reads were pre-processed with the Torrent Suite v.5.8.0 (Thermo Fisher Scientific Inc.) and a fastq file was obtained for each barcode. Extraction of reads covering the csd HVR relied on the identification of nucleotide sequence coding for the highly conserved protein residues (motif) upstream (e.g., KIIS) and downstream (e.g., IEQIP) of the repetitive region [27]. Protein motives were inferred from about 500 protein sequences covering the csd HVR available in UniprotKB [42] (accessed on 2 August 2021) and aligned with MAFFT [43]. This allowed us to generate two regular expressions (one for the $5^{\prime}$ and $3^{\prime}$ HVR) specifying the DNA based search patterns used to interrogate reads (both in 
forward and in reverse complement). Trimming at the level of these two patterns was carried out and only trimmed reads with a Phred quality score (Q) greater or equal to six (probability of incorrect base call less than $25 \%$ ) at each nucleotide position were retained and exported as a fastq file. Moreover, to filter out additional low-quality reads, DNA sequences were clustered together and clusters presenting less than 10 reads were discarded. The obtained smaller fastq files were quality checked using the fastqc tool (http://www.bioinformatics.bbsrc.ac.uk/projects/fastqc/; accessed on 2 August 2021), which points out high quality sequences. Finally, to obtain the csd alleles, reads were translated to small peptides. All analyses were implemented in Python 2.7.

\subsubsection{Quality Control of csd Alleles}

Obtained protein sequences were considered functional csd alleles and were retained for further analyses if they satisfied the following criteria: (i) presence of both HVR flanking protein motives and absence of any stop codon (indels would disrupt the coding frame); (ii) alleles detected in only one sample with a relative frequency (within sample) of reads coding for the defined allele greater than 0.0164, which represents the median minimum relative abundance of the alleles detected in more than one sample; and (iii) alleles detected in at least two honey samples, irrespective of their read abundance. Rarefaction curves were used to evaluate the sequencing efforts in terms of captured variability. For each sample, the average number of functional alleles was plotted as a function of the percentage of sequenced reads, randomly sampled (without replacement). One hundred different sets of sampled reads were used to compute the average number of functional alleles. Analyses were implemented in Python 2.7.

\subsubsection{Evaluation of $c s d$ Polymorphims}

The full set of functional alleles was imported in Jalview v.2.11.1.3 [44], redundancy was removed, and pairwise alignments were performed using the default alignment parameters. For each alignment (pair of alleles), differences were evaluated as proposed by Lechner et al. [21] and also applied by Zareba et al. [24] by using an index that considered the difference in the HVR length $\left(\Delta \mathrm{L}_{\mathrm{HVR}}\right)$, which was summed to the number of amino acid substitutions ( $\mathrm{N}_{\mathrm{SAP}}$; non identical residues). A multiple sequence alignment of functional alleles was obtained by using MAFFT [43]. Analyses were also carried out within the honey sample based on the specific allelic set. R v.3.6.0: [45] was used to elaborate data and generate figures. A BLASTP search (https://blast.ncbi.nlm.nih.gov/Blast.cgi; accessed on August 2021) was carried out to classify alleles as novel.

\subsubsection{Evaluation of Honey Sample Similarity}

Similarity of the analyzed honey samples was investigated via a principal component analysis (PCA) on a binary data matrix accounting for the presence (1) or absence (0) of a csd allele. The matrix had size $=n \times m$; where $n$ was the number of samples whereas $m$ was the number of non-identical alleles identified in the whole dataset of honey samples. To carefully handle this data type, logistic PCA was applied [46]. Moreover, based on this matrix, we also evaluated sample diversity by means of the Jaccard index (J). A dissimilarity matrix (1-J) was computed and hierarchical clustering was applied to it. As a clustering method, we applied both single and complete linkage. Finally, multidimensional scaling (MDS) was applied to the dissimilarity matrix. Analysis was carried out in R v.3.6.0 (package logisticPCA; functions cv.lpca, logpca_model, dist, and cmdscale).

\section{Results}

\subsection{Sequenced Reads and Identified csd Alleles}

Table 1 summarizes the sequencing statistics and the identified csd alleles from the analyzed honey samples. The amplicon-based semiconductor sequencing of the targeted csd gene region produced a total of 1,524,796 reads. Read counts ranged from 1341 to 414,002 for H12 and H3, respectively. Reads were then translated and filtered according to 
the presence of the $5^{\prime}$ (e.g., KIIS) and $3^{\prime}$ (e.g., IEQIP) amino acid motifs, the highly conserved HVR flanking regions $[20,21,23,27]$, and the absence of stop codons. The proportion of these reads coding for retained protein alleles over all reads was $75.3 \%$ and ranged from $48.3 \%$ (H7) to $97.5 \%$ (H6). H10 was the sample with the highest number of protein alleles $(n=61)$ and $\mathrm{H} 11$ and $\mathrm{H} 12$ were the samples that had the lowest number $(n=10)$. Table S1 reports the complete list of all alleles identified from each sample with their relative abundance. The Pearson's correlation coefficient $(r)$ between the number of sequenced reads or the number of retained reads per sample and the number of putative functionally different protein alleles per sample was low $(r=0.28, p=0.37$ and $r=0.22, p=0.48$, respectively). Considering all the honey samples, we identified a total of 160 unique csd protein alleles (Table S2), of which 114 (71.25\%) were private alleles (i.e., detected in only one honey sample). Figure S1 shows the distribution (presence/absence) across samples of these 160 alleles. Rarefaction curves (Figure S2) pointed out that all the possible alleles were detected as curves quickly reached a plateau. In fact, it was possible to observe that the whole set of alleles specific to each sample was detected when less than the $30 \%$ of the reads were sampled (range 14-29\%). The number of private alleles per sample ranged from two (H4 and H11) to 41 (H10) and was highly correlated with the total number of alleles identified per sample $\left(r=0.97, p=3.6 \times 10^{-7}\right)$. Of the 160 unique alleles, 88 were novel (i.e., not yet reported in GenBank). The largest number of novel alleles was identified in H10 $(n=40)$, which was also the sample with the largest number of all alleles $(n=61)$ and of private alleles $(n=41)$. H12 did not have any novel alleles as all 10 alleles identified from this sample were also already deposited in GenBank. The number of novel functional alleles identified per sample was highly correlated with the total number of identified alleles per sample $\left(r=0.95 ; p=2.3 \times 10^{-6}\right)$, but was not correlated with the number of sequenced reads per sample or the number of functional retained reads per sample $(r=0.04$, $p=0.89$ and $r=0.041, p=0.89$, respectively).

The list of $c s d$ protein alleles identified in the different samples with a relative abundance $>5 \%$ is reported in Table 2. Honey samples had from one (H6 and H10) to five (H12) abundant alleles. On average, $3 \pm 1$ alleles with at least this abundance were detected in each honey sample. Among the most abundant alleles, only four were novel alleles, detected in three honey samples (H3, H7, and H9; Table 2). Some alleles were identified in more than one sample: one allele was identified in two different samples (H1 and H2); three alleles were identified in three different samples ( $\mathrm{H} 2, \mathrm{H} 10$, and $\mathrm{H} 12 ; \mathrm{H} 5, \mathrm{H} 7$, and $\mathrm{H} 11$; $\mathrm{H} 5, \mathrm{H} 8$, and H11); one allele was identified in five samples ( $\mathrm{H} 2, \mathrm{H} 4, \mathrm{H} 6, \mathrm{H} 8$, and $\mathrm{H} 11)$.

\subsection{Diversity of csd Protein Alleles}

We then investigated the level of genetic diversity at the $c s d$ gene considering all of the analyzed samples together (thereafter indicted as population-wide analysis) or considering only data within each sample separately. For this specific purpose, we used the HVR length $\left(\Delta \mathrm{L}_{\mathrm{HVR}}\right)$ and the number of amino acid substitutions $\left(\mathrm{N}_{\mathrm{SAP}}\right)$ between all allele pairs.

The HVR length ranged from 35 to 53 residues, with a mean \pm standard deviation of $38 \pm 5$ (median $=37$ ). No relevant deviations emerged in the analysis of the single samples (Table S3 and Figure 1a). Based on pairwise comparisons, two alleles had on average a $\Delta \mathrm{L}_{\mathrm{HVR}}=5$ (s.d. = 4). Within samples, $\Delta \mathrm{L}_{\mathrm{HVR}}$ values ranged from $3.33 \pm 2.83(\mathrm{H} 7)$ to $8.47 \pm 7.07$ (H11). Considering the median values, $\Delta \mathrm{L}_{\mathrm{HVR}}$ ranged from three (H2 and $\left.\mathrm{H} 7\right)$ to seven (H12). Details are provided in Table S3 and Figure $1 \mathrm{~b}$. 
Table 2. Most abundant csd alleles ( $>5 \%$ ) identified in the analyzed honey samples. Data are sorted by sample ID and by relative abundance.

\begin{tabular}{|c|c|c|c|}
\hline Sample ID ${ }^{1}$ & $c s d$ Protein Allele Sequence ${ }^{2}$ & Abundance \% & Novel $^{3}$ \\
\hline H1 & KIISSLSKNTIHNNNYKYNYNNNNNYNNNYKKLQYYNINYIEQIP & 53.4 & \\
\hline H1 & KIISSLSNKTIHNNNNYKKLYYNINYIEQIP & 9.7 & \\
\hline $\mathrm{H} 1$ & KIISSLSNNYNYSNYNNYNNNYNNYKKLYYNINYIEQIP ‡ & 8.9 & \\
\hline $\mathrm{H} 2^{\circ}$ & KIISSLSNSCNYSNNYYNKKLYYNIINIEQIP † & 53.7 & \\
\hline $\mathrm{H} 2^{\circ}$ & KIISSLSNNYNYSNYNNYNNNYNNYKKLYYNINYIEQIP ‡ & 30.2 & \\
\hline $\mathrm{H} 2{ }^{\circ}$ & KIISSLSNKTIHNNNNYKPYYNINYIEQIP ** & 7.7 & \\
\hline H3 & KIISSLSNNYKYSNYNNYNNYNNKKLYYNIINIEQIP & 40.0 & Yes \\
\hline H3 & KIISSLSNKTIHNNNNYNNYKKLYYNIINIEQIP & 12.4 & Yes \\
\hline $\mathrm{H} 3$ & KIISSLSNKTIHNNNYKYNYNNNNNYKKLQYYNIINIEQIP & 6.3 & \\
\hline $\mathrm{H} 4^{\circ}$ & KIISSLSNKTIHNNNNYKPYYNINYIEQIP ** & 83.6 & \\
\hline $\mathrm{H} 5^{\circ}$ & KIISSLSSNYNSNNYNNYNNYKQLCYNINYIEQIP @ & 39.6 & \\
\hline $\mathrm{H} 5^{\circ}$ & KIISSLSNNYKYSNYNNYNNYNKKLYYKNYIINIEQIP & 12.0 & \\
\hline $\mathrm{H} 5^{\circ}$ & KIISSLSNNYNYNNKYNYNNNYNKKLYYNIINIEQIP § & 8.5 & \\
\hline H6 & KIISSLSNKTIHNNNNYKPYYNINYIEQIP ** & 93.1 & \\
\hline H7 & KIISSLSNNYNYNNKYNYNNNYNKKLYYNIINIEQIP § & 38.2 & \\
\hline H7 & KIISSLSNKTIHNNNKYNYNNNYNNNCKKLYYNINYIEQIP & 8.9 & Yes \\
\hline H8 & KIISSLSNKTIHNNNNYKPYYNINYIEQIP ** & 33.3 & \\
\hline H8 & KIISSLSSNYNSNNYNNYNNYKQLCYNINYIEQIP @ & 25.9 & \\
\hline H8 & KITSSLSNNYNSNNYNKYNYNNSKKLYYNINYIEQIP & 13.2 & \\
\hline H8 & KIISSLSNKTIHNNNNYKYNYNNNNYKNYNNYKKLYYNINYIEQIP & 5.8 & \\
\hline $\mathrm{H} 9$ * & KIISSLSNKTIHNNNNYKYNYNNNNYKPYYNINYIEQIP & 45.0 & \\
\hline $\mathrm{H} 9$ * & KIISSLSNKTIHNNNNYKYNYNNNYNNNNYSKKLYYNINYIEQIP & 10.3 & Yes \\
\hline $\mathrm{H} 9$ * & KIISSLSNNYISNISNYNNNNNSKKLYYNINYIEQIP & 5.2 & \\
\hline H10 & KIISSLSNSCNYSNNYYNKKLYYNIINIEQIP † & 17.6 & \\
\hline $\mathrm{H} 11$ * & KIISSLSSNYNSNNYNNYNNYKQLCYNINYIEQIP @ & 43.8 & \\
\hline $\mathrm{H} 11$ * & KIISSLSNKTIHNNNNYKPYYNINYIEQIP ** * & 32.5 & \\
\hline $\mathrm{H} 11^{*}$ & KIISSLSNNYNYNNKYNYNNNYNKKLYYYNIINIEQIP § & 6.7 & \\
\hline H12 & KITSSLSNNYNSNSYNNYNNNYKKLQYYNIINIEQIP & 37.5 & \\
\hline H12 & KIISSLSNNYNYSNYNNYNNYNNNYNNNYNNNYNNYKKLYYNINYIEQIP & 31.5 & \\
\hline H12 & KIISSLSNKTIHNNNNYKYNYNNNNYNNNNYNNNYNNNCKKLYYNINYIEQIP & 5.4 & \\
\hline H12 & KIISSLSNNYKYSNYNNYNNYNNNSKKLYKNYIINIEQIP & 5.3 & \\
\hline H12 & KIISSLSNSCNYSNNYYNKKLYYNIINIEQIP + & 5.1 & \\
\hline
\end{tabular}

${ }^{1}$ Samples provided by the same beekeeper are marked with the same symbol $\left({ }^{*}\right.$ or $\left.{ }^{\circ}\right) .{ }^{2}$ The same alleles identified in different samples are marked with the same symbol $\left(\ddagger^{,+, * *, @}\right.$ and $\left.{ }^{\S}\right) .{ }^{3}$ Alleles that were not present in NCBI Database (August 2021). Details are reported in Tables S1 and S2.

Out of 12,720 pairwise alignments (Figure 2$)$, the global sequence diversity $\left(\Delta \mathrm{L}_{\mathrm{HVR}}+\mathrm{N}_{\mathrm{SAP}}\right)$ ranged from 0 (3 alignments; 0.02\%) to 29 ( 1 alignment; $0.008 \%$ ). On average, 12 differences (s.d. $=4$, median $=$ mean) characterized the 160 alleles. The samples with the lowest and highest pairwise maximum diversity were H4 ( $\max =19)$ and H12 (max $=29)$, respectively. The averaged diversity $\left(\Delta \mathrm{L}_{\mathrm{HVR}}+\mathrm{N}_{\mathrm{SAP}}\right)$ ranged from $9.7(\mathrm{H} 7)$ to $15.1(\mathrm{H} 11)$. Considering the median $\Delta \mathrm{L}_{\mathrm{HVR}}+\mathrm{N}_{\mathrm{SAP}}$ values, sample $\mathrm{H} 7 \mathrm{had}$ the smallest $(n=10)$ and samples $\mathrm{H} 11$ and $\mathrm{H} 12$ had the largest $(\mathrm{n} .=14)$ number of differences, the details of which are included in Table S3 and Figure 1c. It was interesting to note that the honey samples (H11 and H12) that had the lowest number of $c s d$ protein alleles $(n=10)$ had also the highest averaged diversity values (15.1 and 14.7, respectively) and that there was a low negative correlation across all samples between the number of alleles and the average number of sequence diversity $(r=-0.35 ; p=0.26)$. Figure S3 shows the multiple sequence alignment of the 160 protein alleles. 
(a)

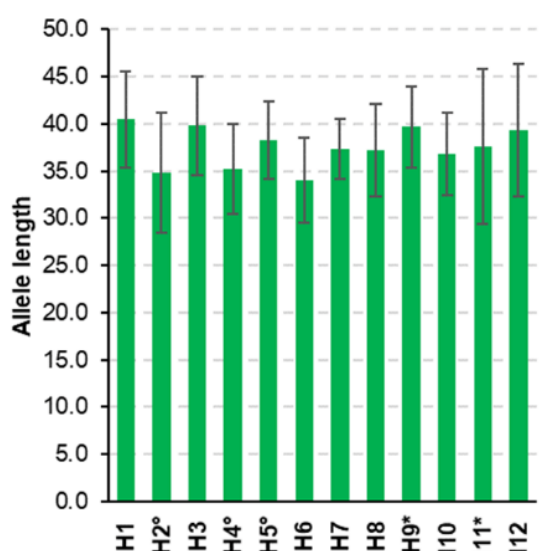

(b)

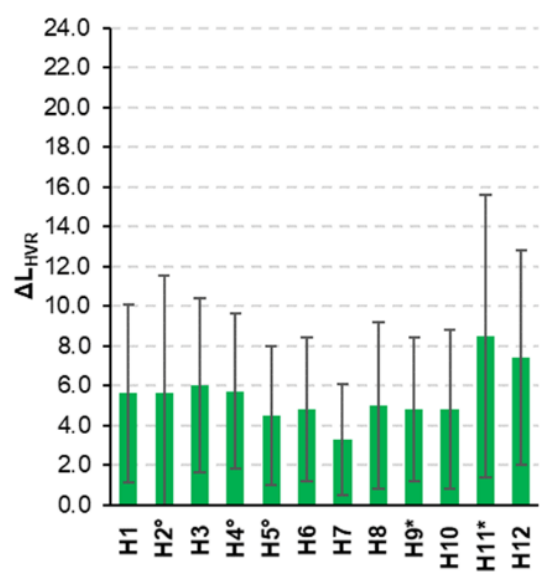

(c)

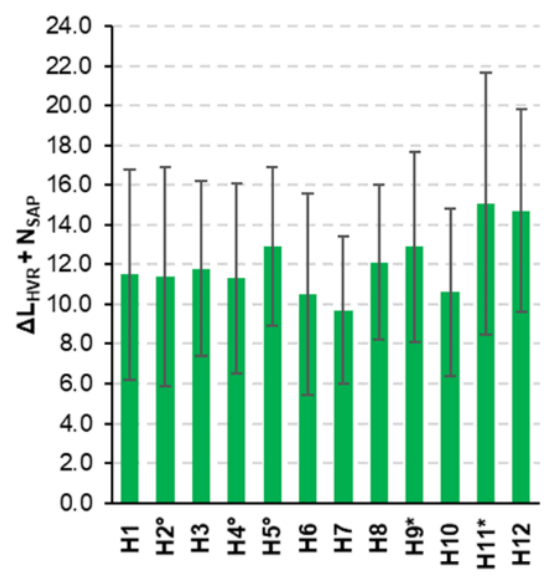

Figure 1. Study of the within sample HVR csd variability. (a) Allele length (mean \pm s.d.); (b) $\Delta \mathrm{L}_{\mathrm{HVR}}$ (mean \pm s.d.); (c) Total differences $\left(\Delta \mathrm{L}_{\mathrm{HVR}}+\mathrm{N}_{\mathrm{SAP}}\right.$; mean \pm s.d.). ${ }^{\circ}$ Samples belonging to the same beekeeper. ${ }^{*}$ Samples belonging to the same beekeeper.

(a)

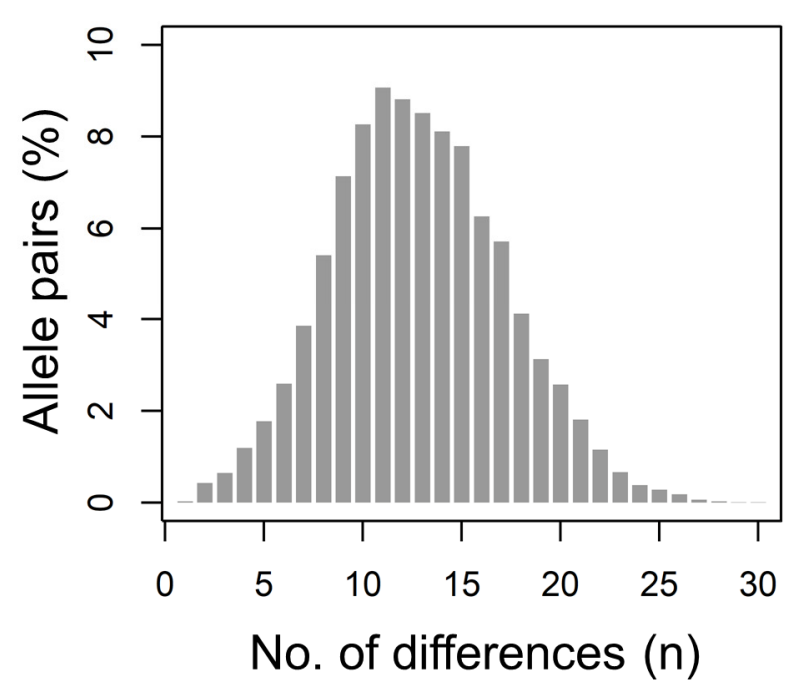

(b)

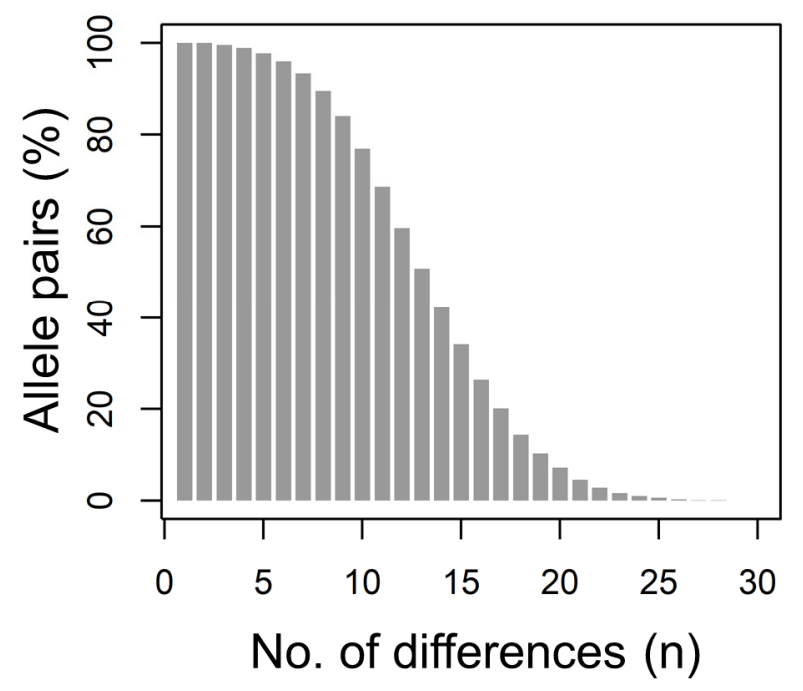

Figure 2. Study of the HVR $c s d$ variability via pairwise alignment of 160 non-identical alleles identified in the investigated honey samples. Differences considered the $\Delta \mathrm{L}_{\mathrm{HVR}}+\mathrm{N}_{\mathrm{SAP}}$ values. (a) Distribution of the HVR differences (alignments presenting $n$ differences). (b) Cumulative distribution of the HVR differences (\% of alignments presenting $\geq n$ differences).

\subsection{Honey Sample Similarity}

Similarity between honey samples obtained from the distribution (presence/absence) of the identified csd alleles was initially evaluated via logistic PCA. This analysis, considering the global properties of the dataset, pointed out a major group of samples without any specific structure (Figure 3a). Two outlier samples emerged-H3 and H10-an expected result as those were the samples with the highest number of detected alleles, most of them being private. Samples $\mathrm{H} 4$ and $\mathrm{H} 5$, two out of three samples coming from the same beekeeper, showed close results to each other. Based on the Jaccard index and locally comparing pairs of samples (sample specific alleles), the similarities values ranged from 0 (H4 and H12) to 0.35 (H5 and H6). Samples H2, H4, and H5, belonging to the same beekeeper, did not present high similarity values (from $\mathrm{J}=0.06$ to $\mathrm{J}=0.23$ ). For the second 
set of honey samples (H9 and H11) derived from the same beekeeper, a low similarity index was retrieved $(\mathrm{J}=0.13)$. Similarities are presented in Supplementary Table S4 and Figure $3 b$.

(a)

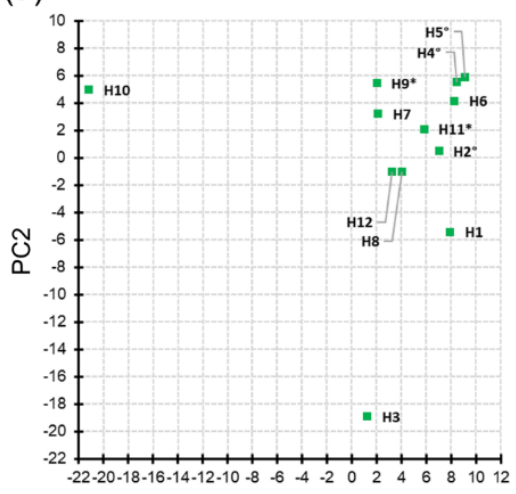

(c)

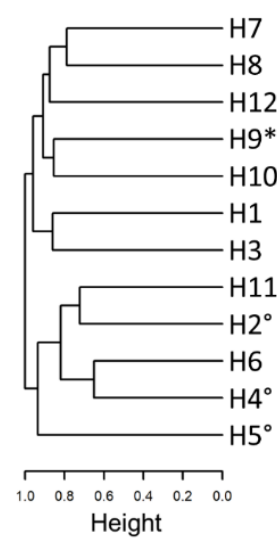

(d)

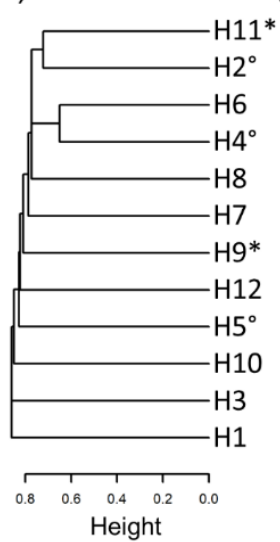

(b)

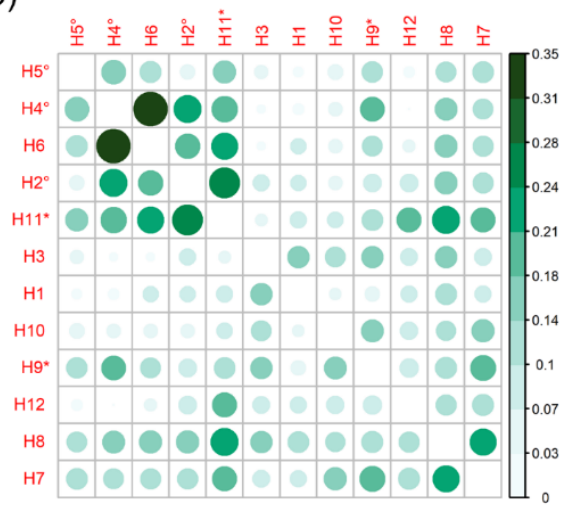

(e)

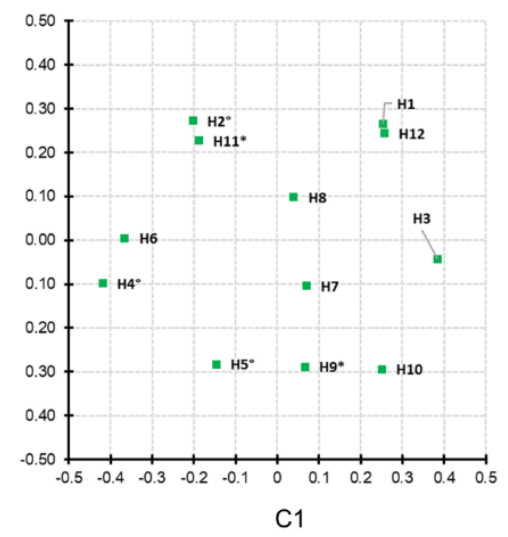

Figure 3. Analyses of honey sample similarity: (a) logistic PCA; (b) Jaccard similarity coefficient; (c) single-linkage clustering based on Jaccard distance; (d) complete-linkage clustering based on Jaccard distance; (e) multidimensional scaling of the Jaccard distance matrix. Samples provided by the same beekeeper are marked with the same symbol $\left({ }^{*}\right.$ or $\left.{ }^{\circ}\right)$.

Clustering based on the complete linkage approach graphically evidenced the similarities presented via the J matrix, highlighting high similarity between samples $\mathrm{H} 4$ and $\mathrm{H} 6$ and between $\mathrm{H} 2$ and $\mathrm{H} 11$ (Figure 3c). Moreover, two main groups of samples emerged in this analysis, one of these comprising the three samples $\mathrm{H} 2, \mathrm{H} 4$, and $\mathrm{H} 5$ obtained from the same beekeeper. Single linkage hierarchical clustering confirmed the H4 and $\mathrm{H} 6$ and the $\mathrm{H} 2$ and $\mathrm{H} 11$ clusters (Figure 3d). This analysis also confirmed the higher dissimilarity of samples H1, H3, and H10 that emerged with the logistic PCA. The multidimensional scaling plot returned similar results, summarizing the similarity analyses in 2D (Figure 3e).

\section{Discussion}

The csd gene has a key role in sex determination in A. mellifera [3]. The analysis of the sequence variability in the HVR of this gene can provide information useful to monitor the level of inbreeding in a honey bee population [23-28]. It has also been suggested that csd may play a role in controlling the balance between inbreeding and outbreeding in honey bee reproduction $[11,17,23]$. Considering that heterozygosity at this gene is essential to generate vital females, several studies have investigated csd sequence diversity, demonstrating that a large number of functional alleles exist in all honey bee populations [21,23-29]. These studies have mainly been carried out by Sanger sequencing the HVR from drones of different colonies, in order to maximize the probability of detecting the two alleles of 
the queen bees [23,24,28] or from workers after cloning the amplicons [25]. The uneven distribution of many infrequent alleles suggests that the diversity of the csd gene is largely underestimated [23]. Therefore, it is necessary to further extend the sequence analysis of this gene to better understand the mechanisms that generate and spread different alleles and to better investigate the role of this locus in maintaining diversity in honey bee populations [23].

The use of next generation sequencing can increase the amount of sequencing data to a few orders of magnitude, which is useful for an extended analysis of the sequence diversity at targeted genes. In this study, we tested the application of next generation semiconductor-based sequencing technology (Ion Torrent/S5) coupled with honey eDNA as the source of honey bee genetic information to obtain massive sequencing data for the analysis of csd gene variability at the population level.

We successfully produced a large number of sequence information that we filtered to overcome some of the problems derived by the applied sequencing technology and by the matrix from which honey bee DNA was recovered. The errors generated by the sequencing technology were removed with a pipeline that considered read quality and the expected in-frame variability to produce functional proteins, flanked by specific residues. About $25 \%$ of the sequencing reads were discarded, leaving about 1.1 million useful reads that were subsequently analyzed to define the level of variability in the $c s d$ gene that was recovered from the investigated honey samples. A larger number of reads, which could eventually be possible to generate with this sequencing technology (using different chips and chemistry) or using other sequencing technologies (e.g., Illumina) would not be needed as there was a very poor correlation $(r=0.28)$ between the number of alleles and the number of reads per sample ( $r=0.23$, if we only considered the retained functional reads). This is also expected if we consider that a colony (from which the honey was obtained) has a finite number of $c s d$ alleles, which are derived from its genetic history: the number of drones that fertilized the queen of the colony from which the honey derived, the number of queens that were eventually part of the family history from which the honey was collected and the contribution of the drifted workers.

One of the problems that we could not completely control was the degradation of the DNA extracted from honey. DNA extracted from commercial honey is usually highly degraded as the food matrix environment and its preservation conditions are not optimal to maintain DNA. Therefore, from this matrix, it is usually possible to amplify, without any biases, short DNA fragments [33,36-38]. To minimize the problems derived by long preservations that would increase DNA degradation, we collected honey samples directly from honeycombs. The amplification of the HVR fragments (about 300-380 bp) was successful in all cases, suggesting that, despite the problem of DNA degradation, honey can be a useful source of DNA for csd sequence analyses. Some biases in the amplification, however, probably occurred, as deduced from the number of the most abundant alleles obtained from the analyzed samples (Table 2). In three samples (H4, H6, and H10), only one allele had a percentage of reads that was $>5 \%$ and these alleles were among the shortest alleles that we considered in the analysis of abundance. This means that these alleles were probably favored in the amplification/sequencing steps, creating some biases. At least two highly prevalent alleles, derived by the two alleles of the queen and, for that reason, with similar abundance, would be expected. This would be true in theory, in the case of no biases in the amplification and sequencing processes. If we also consider all other honey samples, it is possible to note that only in four cases did the two prevalent alleles have a similar or close abundance (H2: 53.7 and 30.2\%; H8: 33.3 and 25.9\%; H11: 43.8 and $32.5 \%$; H12: 37.5 and $31.5 \%$ ). It is worth noting that for H12, which was the sample with the lowest number of sequenced reads, there was also the lowest differences in terms of abundance between the two most prevalent alleles, despite the fact that these two alleles were quite different in terms of size of the considered functional region (37 and 49 residues, respectively). Biases in the abundance of the two queen derived alleles have been also reported in a pilot study that sequenced the csd HVR fragment amplified from honey DNA 
using the Illumina technology [29]. Even if it seems clear that the results derived by these approaches could only be partially considered as semi-quantitative [30,39-41,47], it will be important to evaluate how it could be possible to reduce and then manage the different sources of biases that are derived from the sequencing technologies and the degradation of the honey DNA.

Despite the potential biases that we discussed above, the use of honey DNA as a source of honey bee csd sequence information offers the possibly to detect most, if not all, of the $c s d$ alleles present in a colony, opening new opportunities to investigate $c s d$ diversity at population-wide levels. The results we obtained confirmed the presence of many infrequent alleles in the A. mellifera population. On average, each sample had about 23 different alleles, which is close to the number of patrilines present in a family as estimated by microsatellite analyses [48,49]. We also have to consider that at least two of these detected alleles might be from the maternal lineage (i.e., queen). A study that analyzed A. m. carnica colonies in mainland mating apiaries reported an average number of effective males equal to 20 [48] and another study that investigated colonies from different $A$. mellifera subspecies reported a range of 7-20 patrilines [49]. The first mentioned study [48] also detected drifted workers from other families $(<5 \%)$, which can contribute to an increase in the number of paternal alleles in a colony. In both microsatellite derived estimations [48,49] several paternal lineages were present at very low frequency, also matching the low frequency (or abundance in our case) of several alleles that we identified from honey. For a few honey samples (H3, H9, and H10; Table 1) that had a larger number of alleles, we could suppose a more complicated genetic history probably due to one or more of the following situations: the subsequent presence of different queens leading the colony; the exchange of the comb to more than one colony; and/or a high rate of drift or combinations of different nuclei. To verify these hypotheses, we are designing studies that will make it possible to verify the information retrieved from the honey with information directly obtained from the honey bees of that colony.

A large proportion of alleles (55\%) were also newly detected in this study. We could also predict that more new alleles would be discovered if the number of analyzed samples is increased. Even if we could not completely exclude that few of these alleles are derived by sequencing errors (which we could not completely eliminate, as in all sequencing experiments), clearly the large number of csd alleles may raise some questions (i) on the population dynamics and spreading or extinction of these alleles; (ii) on the mechanisms of generation of new alleles; (iii) on their role in defining a balance between inbreeding/outbreeding in the honey bee populations [23] and; in turn, (iv) on the usefulness of this locus in estimating and monitoring genetic diversity in A. mellifera. Additional studies are needed to clarify these issues and the approach that we tested here (i.e., massive sequencing from honey DNA) could help to answer, at least in part, some of these questions, if applied to larger scales and in appropriately planned experimental designs.

The analysis of putative functional allele diversity based on the number of amino acid substitutions and allele length differences $\left(\Delta \mathrm{L}_{\mathrm{HVR}}+\mathrm{N}_{\mathrm{SAP}}\right)$ obtained a pairwise distribution of difference almost identical to that also reported in Polish honey bee populations that used Sanger sequencing of the csd HVR [23]. The quite high level of pairwise allele diversity (on average: 12 differences) was a little bit lower than that reported in the Polish populations (on average: about 14-15 differences [23]). This difference could be probably due to the lower range of differences that we observed (0 to 29) than what was reported by [23] (1 to 36). The reasons for this difference could be attributed (i) to the lower number of large alleles that we could amplify/sequence from the degraded honey DNA (as discussed above, a potential bias in our study) than what could be obtained directly from the drone DNA in [23]; (ii) to a higher level of functional inbreeding in the Italian population analyzed in our study (from a limited number of colonies) than in the Polish populations that were also investigated from a larger number of colonies [23]; and/or (iii) to different levels of subspecies introgression (which usually increases variability) between the Italian and the Polish honey bee populations. This latter aspect could be 
hypothesized considering the high rate of hybridization of the original dark bee in Poland, as demonstrated by the mitochondrial and nuclear DNA markers [50], and the relatively lower level of hybridization that might have experienced the A. m. ligustica, particularly in the Italian region from which the analyzed samples originated (Emilia-Romagna), as could be inferred from our recent mtDNA investigation [34]. Other studies are needed to better address these questions.

All honey samples that we investigated could be easily differentiated using the csd allele information. Even if it is not completely appropriate, we could extend this clear differentiation to all families from which the honey is derived. In fact, honey does not only contain DNA traces from the family from which it was sampled (in general, the most important source of honey bee DNA), but also provides hints from the whole history that it had including the fingerprinting of more than one queen (in the case of queen substitution), drifted individuals, the subsequent use or re-use of the comb, which all together may have contributed to distinguish their csd profiles. Therefore, it is possible to propose the use of the $c s d$ sequence variability as a potential tool to trace and authenticate the origin of the honey and, if applied to the honey bees, as a simple genetic footprint of the colony that produced it. Honey samples obtained from different apiaries of the same beekeeper were more similar in terms of csd profile only in one case ( $\mathrm{H} 4$ and $\mathrm{H} 5)$. This means that these samples were probably derived from queens of the same genetic line. It was not possible, however, to trace back the genetic information of the queens as the beekeeper did not record any data. Genomic analyses of the honey bees sampled from the same colonies will provide additional information to support what obtained from the honey-derived csd gene sequences. All remaining honey samples could not be grouped according to beekeeper origin, suggesting that quite a large heterogeneity was present in the colonies and apiaries that provided the honey samples.

\section{Conclusions}

Environmental DNA contained in the honey can be analyzed for many different purposes. In this study, we further expanded the usefulness of honey eDNA by targeting honey bee nuclear DNA to investigate, using a next generation sequencing technology, the variability of the key gene for sex determination in A. mellifera. Technical issues can be managed and considered to correctly interpret the final results that were, in general, in agreement with those reported by conventional Sanger sequencing approaches based on individual bee analyses. The tested approach, however, has the possibility of extending the amount of information that is needed to understand, from a population genetic perspective, all the open questions derived by this hypervariable locus. Other studies are needed to complete the analysis of the potential biases that the combined use of next generation sequencing and honey DNA can introduce in this context. As a general outlook, it will be possible in the future to use csd information retrieved from the honey to implement breeding plans in honey bees that would need data on the genetic closeness of the families, which might be determined by the number and differences of the csd alleles they carry.

Supplementary Materials: The following are available online at https: / www.mdpi.com/article / 10.3390/insects12100868/s1: Table S1: csd alleles detected in the analyzed honey samples; Table S2: Non-identical csd alleles detected in the analyzed honey samples; Table S3: Diversity of the csd alleles. Statistics are presented within sample; Table S4: Similarity between samples measured using the Jaccard index; Figure S1: Distribution of the 160 csd alleles across the honey samples (presence: green; absence: white); Figure S2: Rarefaction curves obtained for the twelve honey samples; Figure S3: Multiple sequence alignment of the $160 \mathrm{csd}$ alleles.

Author Contributions: Conceptualization, L.F.; Formal analysis, S.B., A.R., V.J.U., V.T, G.S. and M.B.; Investigation, S.B., A.R., V.J.U., V.T., G.S. and L.F.; Software, S.B.; Data curation, S.B.; Writing-original draft preparation, L.F. and S.B.; Writing-review and editing, L.F. and S.B.; Visualization, S.B.; Supervision, L.F.; Project administration, L.F.; Resources, L.F.; Funding acquisition, L.F. All authors have read and agreed to the published version of the manuscript. 
Funding: This research was funded by the University of Bologna 2020 RFO program, by Regione Emilia-Romagna, BEE-RER-2 project-CUP E39J21000260007-del Regolamento (UE) no. 1308/2013-(OCM Apicoltura).

Institutional Review Board Statement: Not applicable.

Informed Consent Statement: Not applicable.

Data Availability Statement: Sequencing data covering the trimmed HVR as well as the set of 160 csd alleles are available in the EMBL-EBI European Nucleotide Archive (ENA) repository (http:/ / www.ebi.ac.uk/ena; accessed on 23 September 2021) under the study accession PRJEB47528.

Acknowledgments: The authors thank the beekeepers and beekeeper associations for providing the honey samples.

Conflicts of Interest: The authors declare no conflict of interest. The funders had no role in the design of the study; in the collection, analyses, or interpretation of data; in the writing of the manuscript, or in the decision to publish the results.

\section{References}

1. Heimpel, G.E.; de Boer, J.G. Sex determination in the Hymenoptera. Annu. Rev. Entomol. 2008, 53, 209-230. [CrossRef] [PubMed]

2. Dzierzon, J. Gutachten über die von Herrn Direktor Stöhr im ersten und zweiten Kapitel des General-Gutachtens aufgestellten Fragen. Eichstädter Bienenztg. 1845, 1, 119-121.

3. Beye, M.; Hasselmann, M.; Fondrk, M.K.; Page, R.E., Jr.; Omholt, S.W. The gene csd is the primary signal for sexual development in the honeybee and encodes an SR-type protein. Cell 2003, 114, 419-429. [CrossRef]

4. Whiting, P.; Whiting, A.R. Diploid males from fertilized eggs in Hymenoptera. Science 1925, 62, 437. [CrossRef] [PubMed]

5. Woyke, J.; Knytel, A. The chromosome number as proof that drones can arise from fertilizer eggs of the honeybee. J. Apic. Res. 1966, 5, 149-154. [CrossRef]

6. Mackensen, O. Viability and sex determination in the honey bee (Apis mellifera L.). Genetics 1951, 36, 500-509. [CrossRef]

7. Woyke, J. Drone larvae from fertilised eggs of the honeybee. J. Apic. Res. 1963, 2, 19-24. [CrossRef]

8. Woyke, J. Effect of sex allele homo-heterozygosity on honeybee colony population and on their honey production. 1. Favourable development conditions and unrestricted queens. J. Apic. Res. 1980, 19, 51-63. [CrossRef]

9. Woyke, J. Effect of sex allele homo-heterozygosity on honeybee colony population and on their honey production. 2. Unfavourable development conditions and restricted queens. J. Apic. Res. 1981, 20, 148-155. [CrossRef]

10. Tarpy, D.R.; Page, R.E. The curious promiscuity of queen honey bees (Apis mellifera): Evolutionary and behavioral mechanisms. Ann. Zool. Fenn. 2001, 38, 255-265.

11. Page, R.E.J.; Marks, R.W. The population genetics of sex determination in honey bees: Random mating in closed populations. Heredity 1982, 48, 263-270. [CrossRef]

12. Kalmus, H.; Smith, C.A.B. Production of pure lines in bees. J. Genet. 1949, 49, 153-158. [CrossRef] [PubMed]

13. Mackensen, O. Further studies on a lethal series in the honey bee. J. Hered. 1955, 46, 72-74. [CrossRef]

14. Hachinohe, Y.; Jimbu, M. Occurrence of the lethal eggs in the honeybee. Bull. Nat. Inst. Agric. Sci. Ser. G. 1958, 14, 123-130.

15. Laidlaw, H.H., Jr.; Gomes, F.P.; Kerr, W.E. Estimation of the number of lethal alleles in a panmictic population of Apis mellifera L. Genetics 1956, 41, 179-188. [CrossRef] [PubMed]

16. Adams, J.; Rothman, E.D.; Kerr, W.E.; Paulino, Z.L. Estimation of the number of sex alleles and queen matings from diploid male frequencies in a population of Apis mellifera. Genetics 1977, 86, 583-596. [CrossRef]

17. Yokohama, S.; Nei, M. Population dynamics of sex-determining alleles in honey bees and self-incompatibility alleles in plants. Genetics 1979, 91, 609-626. [CrossRef]

18. Hasselmann, M.; Beye, M. Signatures of selection among sex-determining alleles of the honey bee. Proc. Natl. Acad. Sci. USA 2004, 101, 4888-4893. [CrossRef]

19. Hasselmann, M.; Beye, M. Pronounced differences of recombination activity at the sex determination locus of the honeybee, a locus under strong balancing selection. Genetics 2006, 174, 1469-1480. [CrossRef]

20. Hasselmann, M.; Vekemans, X.; Pflugfelder, J.; Koeniger, N.; Koeniger, G.; Tingek, S.; Beye, M. Evidence for convergent nucleotide evolution and high allelic turnover rates at the complementary sex determiner gene of Western and Asian honeybees. Mol. Biol. Evol. 2008, 25, 696-708. [CrossRef]

21. Lechner, S.; Ferretti, L.; Schöning, C.; Kinuthia, W.; Willemsen, D.; Hasselmann, M. Nucleotide variability at its limit? Insights into the number and evolutionary dynamics of the sex-determining specificities of the honey bee Apis mellifera. Mol. Biol. Evol. 2014, 31, 272-287. [CrossRef] [PubMed]

22. Cho, S.; Huang, Z.Y.; Green, D.R.; Smith, D.R.; Zhang, J. Evolution of the complementary sex-determination gene of honey bees: Balancing selection and trans-species polymorphisms. Genome Res. 2006, 16, 1366-1375. [CrossRef]

23. Zareba, J.; Blazej, P.; Laszkiewicz, A.; Sniezewski, L.; Majkowski, M.; Janik, S.; Cebrat, M. Uneven distribution of complementary sex determiner (csd) alleles in Apis mellifera population. Sci. Rep. 2017, 7, 2317. [CrossRef] 
24. Kaskinova, M.D.; Gataullin, A.R.; Saltykova, E.S.; Gaifullina, L.R.; Poskryakov, A.V.; Nikolenko, A.G. Polymorphism of the hypervariable region of the csd gene in the Apis mellifera L. population in Southern Urals. Russian J. Gen. 2019, 55, 267-270. [CrossRef]

25. Wang, Z.; Liu, Z.; Wu, X.; Yan, W.; Zeng, Z. Polymorphism analysis of csd gene in six Apis mellifera subspecies. Mol. Biol. Rep. 2012, 39, 3067-3071. [CrossRef] [PubMed]

26. Bilodeau, L.; Avalos, A.; Danka, R.G. Genetic diversity of the complementary sex-determiner (csd) gene in two closed breeding stocks of Varroa-resistant honey bees. Apidologie 2020, 51, 1125-1132. [CrossRef]

27. Bilodeau, L.; Elsik, C. A scientific note defining allelic nomenclature standards for the highly diverse complementary sexdeterminer (csd) locus in honey bees. Apidologie 2021, 52, 749-754. [CrossRef]

28. Hyink, O.; Laas, F.; Dearden, P.K. Genetic tests for alleles of complementary-sex-determiner to support honeybee breeding programmes. Apidologie 2013, 44, 306-313. [CrossRef]

29. Kolics, É.; Parrag, T.; Házi, F.; Szepesi, K.; Heltai, B.; Mátyás, K.; Kutasy, B.; Virág, E.; Taller, J.; Orbán, L.; et al. An alternative, high throughput method to identify csd alleles of the honey bee. Insects 2020, 11, 483. [CrossRef] [PubMed]

30. Utzeri, V.J.; Schiavo, G.; Ribani, A.; Tinarelli, S.; Bertolini, F.; Bovo, S.; Fontanesi, L. Entomological signatures in honey: An environmental DNA metabarcoding approach can disclose information on plant-sucking insects in agricultural and forest landscapes. Sci. Rep. 2018, 8, 9996. [CrossRef] [PubMed]

31. Bovo, S.; Ribani, A.; Utzeri, V.J.; Schiavo, G.; Bertolini, F.; Fontanesi, L. Shotgun metagenomics of honey DNA: Evaluation of a methodological approach to describe a multi-kingdom honey bee derived environmental DNA signature. PLoS ONE 2018, 13, e0205575. [CrossRef] [PubMed]

32. Bovo, S.; Utzeri, V.J.; Ribani, A.; Cabbri, R.; Fontanesi, L. Shotgun sequencing of honey DNA can describe honey bee derived environmental signatures and the honey bee hologenome complexity. Sci. Rep. 2020, 10, 9279. [CrossRef]

33. Utzeri, V.J.; Ribani, A.; Fontanesi, L. Authentication of honey based on a DNA method to differentiate Apis mellifera subspecies: Application to Sicilian honey bee (A. m. siciliana) and Iberian honey bee (A. m. iberiensis) honeys. Food Control 2018, 91, $294-301$. [CrossRef]

34. Utzeri, V.J.; Ribani, A.; Taurisano, V.; Banqué, C.H.i.; Fontanesi, L. Distribution of the main Apis mellifera mitochondrial DNA lineages in Italy assessed using an environmental DNA approach. Insects 2021, 12, 620. [CrossRef] [PubMed]

35. Utzeri, V.J.; Ribani, A.; Schiavo, G.; Bertolini, F.; Bovo, S.; Fontanesi, L. Application of next generation semiconductor based sequencing to detect the botanical composition of monofloral, polyfloral and honeydew honey. Food Control 2018, 86, 342-349. [CrossRef]

36. Utzeri, V.J.; Schiavo, G.; Ribani, A.; Bertolini, F.; Bovo, S.; Fontanesi, L. A next generation sequencing approach for targeted Varroa destructor (Acari: Varroidae) mitochondrial DNA analysis based on honey derived environmental DNA. J. Invertebr. Pathol. 2019, 161, 47-53. [CrossRef] [PubMed]

37. Ribani, A.; Utzeri, V.J.; Taurisano, V.; Fontanesi, L. Honey as a source of environmental DNA for the detection and monitoring of honey bee pathogens and parasites. Vet. Sci. 2020, 7, 113. [CrossRef]

38. Ribani, A.; Utzeri, V.J.; Taurisano, V.; Galuppi, R.; Fontanesi, L. Analysis of honey environmental DNA indicates that the honey bee (Apis mellifera L.) trypanosome parasite Lotmaria passim is widespread in the apiaries of the North of Italy. J. Invertebr. Pathol. 2021, 184, 107628. [CrossRef] [PubMed]

39. Ribani, A.; Schiavo, G.; Utzeri, V.J.; Bertolini, F.; Geraci, C.; Bovo, S.; Fontanesi, L. Application of next generation semiconductor based sequencing for species identification in dairy products. Food Chem. 2018, 246, 90-98. [CrossRef]

40. Ribani, A.; Schiavo, G.; Utzeri, V.J.; Bertolini, F.; Geraci, C.; Bovo, S.; Fontanesi, L. Application of next generation semiconductor based sequencing for species identification and analysis of within-species mitotypes useful for authentication of meat derived products. Food Control 2018, 91, 58-67. [CrossRef]

41. Bertolini, F.; Ghionda, M.C.; D'Alessandro, E.; Geraci, C.; Chiofalo, V.; Fontanesi, L. A next generation semiconductor based sequencing approach for the identification of meat species in DNA mixtures. PLoS ONE 2015, 10, e0121701. [CrossRef] [PubMed]

42. UniProt Consortium. UniProt: The universal protein knowledgebase in 2021. Nucleic Acids Res. 2021, 49, D480-D489. [CrossRef] [PubMed]

43. Katoh, K.; Rozewicki, J.; Yamada, K.D. MAFFT online service: Multiple sequence alignment, interactive sequence choice and visualization. Brief Bioinform. 2019, 20, 1160-1166. [CrossRef]

44. Waterhouse, A.M.; Procter, J.B.; Martin, D.M.A.; Clamp, M.; Barton, G.J. Jalview Version 2-A multiple sequence alignment editor and analysis workbench. Bioinformatics 2009, 25, 1189-1191. [CrossRef] [PubMed]

45. R Core Team. R: A Language and Environment for Statistical Computing; R Foundation for Statistical Computing: Vienna, Austria, 2019; Available online: https:/ / www.R-project.org/ (accessed on 2 August 2021).

46. Landgraf, A.J.; Lee, Y. Dimensionality reduction for binary data through the projection of natural parameters. J. Mult. Anal. 2020, 180, 104668. [CrossRef]

47. Porter, T.M.; Hajibabaei, M. Scaling up: A guide to high throughput genomic approaches for biodiversity analysis. Mol. Ecol. 2018, 27, 313-338. [CrossRef] 
48. Neumann, P.; Moritz, R.F.; van Praagh, J. Queen mating frequency in different types of honey bee mating apiaries. J. Apic. Res. 1999, 38, 11-18. [CrossRef]

49. Estoup, A.; Solignac, M.; Cornuet, J.M. Precise assessment of the number of patrilines and of genetic relatedness in honeybee colonies. Proc. R. Soc. Lond. B 1994, 258, 1-7. [CrossRef]

50. Oleksa, A.; Chybicki, I.; Tofilski, A.; Burczyk, J. Nuclear and mitochondrial patterns of introgression into native dark bees (Apis mellifera mellifera) in Poland. J. Apic. Res. 2011, 50, 116-129. [CrossRef] 